\title{
Green Preparation of Sulfonated Polystyrene/Polyaniline/Silver Composites with Enhanced Anticorrosive Properties
}

\begin{abstract}
Guangfu Liao
Correspondence: Guangfu Liao, Hubei Collaborative Innovation Center for Advanced Organic Chemical Materials, Ministry of Education Key Laboratory for The Green Preparation and Application of Functional Materials, Hubei University, Wuhan, Hubei 430062, China. E-mail:lgfhubu@163.com
\end{abstract}

Received: December 22, 2017 Accepted: January 15, 2018 Online Published: January 25, 2018

doi:10.5539/ijc.v10n1p81

URL: https://doi.org/10.5539/ijc.v10n1p81

\begin{abstract}
Sulfonated polystyrene/polyaniline/silver (SPS/PANI/Ag) composites with enhanced anticorrosive properties have been successfully prepared by using SPS microspheres as substrates and utilizing polyvinylpyrrolidone (PVP) as reducing agent and stabilizing agent. Our method is an environmentally friendly method because of the absence of any toxic reagents in the whole process. Fourier transform infrared Spectrum (FTIR), field emission scanning electron microscopy (FESEM), and energy disperse spectroscopy (EDX) results confirmed the formation of pure PANI, SPS/PANI composites, and SPS/PANI/Ag composites. Powder X-ray diffraction (XRD) patterns indicate that the obtained Ag nanoparticles are crystalline. The anticorrosive studies indicate that both SPS/PANI composites and SPS/PANI/Ag composites have enhanced anticorrosive properties in comparison to pure PANI in various corrosive environments.
\end{abstract}

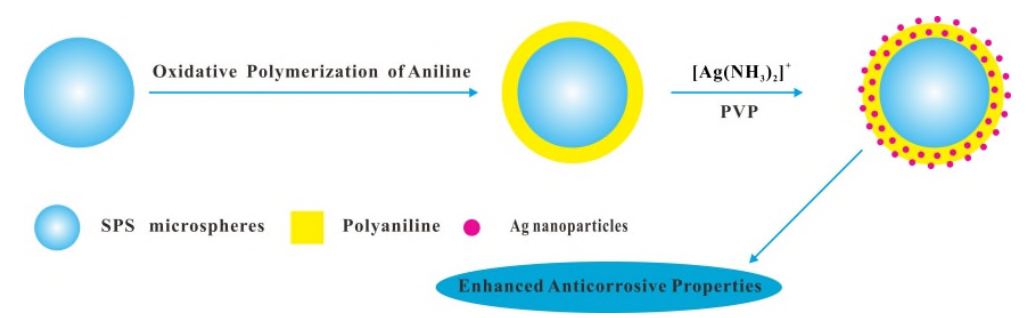

Keywords: sulfonated polystyrene, polyaniline, silver, enhanced anticorrosive properties

\section{Introduction}

Polyaniline (PANI) is now regarded as a prominent anticorrosive material due to its low cost, unique oxidationreduction chemistry, and environmental stability.( Kim, Lee, In, \& Park, 2014) ( Yang et al., 2015) (Han et al., 2017) (Yuan et al., 2013) However, using single PANI particles as corrosive material have a series of problems such as poor processability, easy aggregation, dissatisfactory anticorrosive properties, etc.( Yang, Cao, \& Tan, 2014) To solve the problem, many different approaches have been attempted, and a significant attempt to overcome these drawbacks is that using sulfonated polystyrene (SPS) microspheres as substrates to prepare SPS/PANI composites.( Liu et al., 2008) Using SPS microspheres as substrates can significantly improve the processability of PANI as well as reduce aggregation of PANI because SPS is similar to amphiphilic polymer.( Dai et al., 2011) In addition, the incorporation of silver (Ag) nanoparticles in PANI can obviously promote the anticorrosive properties of PANI because Ag nanopaiticles exhibit excellent environmental stability and anticorrosive properties. (Zhao et al., 2005)

Combined with the above, in this work, we present a green approach to prepare SPS/PANI/Ag composites with enhanced anticorrosive properties through using SPS microspheres as substrates and utilizing PVP as reducing agent and stabilizing agent. Anticorrosive studies show that the prepared SPS/PANI/Ag composites have enhanced anticorrosive properties in comparison to pure PANI and SPS/PANI composites in various corrosive environments.

\section{Materials and Methods}

\subsection{Materials}

Polyvinylpyrrolidone (PVP, $\mathrm{Mw}=40000 \mathrm{~mol} / \mathrm{g})$, absolute ethanol, silver nitrate $\left(\mathrm{AgNO}_{3}, \geq 99.8 \%\right)$, sulfuric acid $\left(\mathrm{H}_{2} \mathrm{SO}_{4}\right.$, $98 \%$ ), hydrochloric acid ( $\mathrm{HCl})$, ammonia, Aniline (An), ammonium persulfate (APS) and waterborne alkyd resin (WAR) were purchased from Sinopharm Chemical Reagent Co., Ltd, China. Aniline was used after distillation. Monodisperse SPS microspheres were prepared according to the method of Deng.( Deng et al., 2012). 


\subsection{Preparation of Pure PANI}

$0.5 \mathrm{~g}$ of aniline and $20 \mathrm{~mL}$ of $2 \mathrm{M} \mathrm{HCl}$ were added into $100 \mathrm{~mL}$ three-necked flask, and then the mixture of aniline and $\mathrm{HCl}$ was stirred in an ice bath for $5 \mathrm{~h}$, finally added $1.2 \mathrm{~g}$ of APS (dissolved in $20 \mathrm{~mL}$ deionized water) aqueous solution by dropping slowly. The polymerization had been proceeding for $24 \mathrm{~h}$ by stirring slowly at $0{ }^{\circ} \mathrm{C}$. The product was centrifuged, washed with deionized water and absolute ethanol several times, and then dried in vacuum at $50{ }^{\circ} \mathrm{C}$ for $24 \mathrm{~h}$.

\subsection{Preparation of SPS/PANI Composites}

SPS powder $(0.3 \mathrm{~g})$ and aniline $(0.05 \mathrm{~g})$ monomer were dispersed in deionized water $(40 \mathrm{~mL})$ and $2 \mathrm{~mL}$ of $2 \mathrm{M} \mathrm{HCl}$ with the aid of ultrasonic. The mixture of aniline and SPS was stirred in an ice bath for $5 \mathrm{~h}$, and then added $0.12 \mathrm{~g}$ of APS (dissolved in $2 \mathrm{~mL}$ deionized water) aqueous solution by dropping slowly. The polymerization had been proceeding for $24 \mathrm{~h}$ by stirring slowly at $0{ }^{\circ} \mathrm{C}$. The product was centrifuged, washed with deionized water and absolute ethanol several times, and then dried in vacuum at $50^{\circ} \mathrm{C}$ for $24 \mathrm{~h}$.

\subsection{Preparation of SPS/PANI/Ag Composites}

SPS/PANI composites $(0.13 \mathrm{~g})$ and PVP $(1 \mathrm{~g})$ was mixed with deionized water $(50 \mathrm{~mL})$ with the aid of ultrasonic. Then, $10 \mathrm{~mL}$ of freshly prepared aqueous solution of $\left[\mathrm{Ag}\left(\mathrm{NH}_{3}\right)_{2}\right]^{+}(0.2 \mathrm{M})$ was quickly added into the above dispersion, magnetically stirred at room temperature for $1 \mathrm{~h}$. Finally, this mixture was kept at $70{ }^{\circ} \mathrm{C}$ and stirred for $7 \mathrm{~h}$ under the atmosphere of nitrogen. The product was separated by centrifugation, and washed with deionized water several times, and then dried in vacuum at $50{ }^{\circ} \mathrm{C}$ for $24 \mathrm{~h}$.

\subsection{Characterization}

Fourier transform infrared spectroscopy (FTIR) analysis of the samples was taken on a Spectrum One FTIR spectrometer (Perkin-Bhaskar-Elmer Co., USA). Crystal structures of the samples were performed on an X-ray diffraction (XRD, D/MAX-IIIC, Japan), taken from $5^{\circ}$ to $90^{\circ}$. The morphology and compenent of the samples were determined by Field emission scanning electron microscopy (FESEM, JSM7100F, Janpan) and corresponding energy-dispersive X-ray spectroscopy (EDX).

\subsection{Anticorrosion Tests}

Throughout this work, Tafel plots were performed using an electrochemical workstation (CHI660D, CH Instruments Inc.) and carried out using a conventional three-electrode electrochemical cell with a Pt plate as counter electrode and an $\mathrm{Ag} / \mathrm{AgCl}$ as reference electrode. The working electrode was the tinplate sample. The room temperature $\left(25^{\circ} \mathrm{C}\right)$ is the experimental temperature. Four tinplate samples were prepared, tinplate coated with waterborne alkyd resin, waterborne alkyd resin with $1 \%(\mathrm{w} / \mathrm{w})$ PANI, waterborne alkyd resin with $1 \%(\mathrm{w} / \mathrm{w})$ SPS/PANI and waterborne alkyd resin with $1 \%$ (w/w) SPS/PANI/Ag, coded as WAR, WAR/P, WAR/SP and WAR/SPA, respectively. $\mathrm{NaCl} 0.6 \mathrm{M}, \mathrm{NaOH} 1 \mathrm{M}$, and $\mathrm{HCl}$ $1 \mathrm{M}$ electrolytes were used as corrosive environment, respectively. During potentiodynamic polarization, the scanning voltage range was $-0.1 \sim 0.1 \mathrm{~V}$ and the scan rate was $1 \mathrm{mV} / \mathrm{s}$.
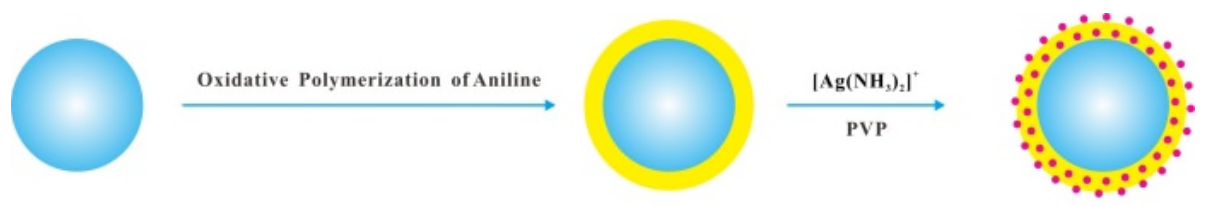

SPS microspheres

Polyaniline

Ag nanoparticles

Figure 1. Schematic illustration of the formation of SPS/PANI/Ag composites

\section{Results and Discussion}

The detailed preparation process of SPS/PANI/Ag composites is illustrated in Figure 1. Firstly, aniline monomer is added into the SPS microspheres aqueous solution and then it is adsorbed onto the surfaces of the SPS microspheres. In this case, SPS/PANI composites are formed by polymerization of aniline on the surface of SPS microspheres. Then, $\left[\mathrm{Ag}\left(\mathrm{NH}_{3}\right)_{2}\right]^{+}$aqueous solution is added into the SPS/PANI composites aqueous solution and then it is adsorbed onto the surfaces of SPS/PANI composites. In this case, SPS/PANI/Ag composites are formed by the reduction of $\left[\operatorname{Ag}\left(\mathrm{NH}_{3}\right)_{2}\right]^{+}$ ions with PVP. Neither additional reducing agent nor toxic organic solvents are added in the whole process. Therefore, our preparative method is environmentally friendly.

The FTIR spectra of pure PANI, SPS/PANI composites, and SPS/PANI/Ag composites is shown in Figure 2. The typical PANI absorption bands at $1597 \mathrm{~cm}^{-1}, 1487 \mathrm{~cm}^{-1}, 1300 \mathrm{~cm}^{-1}, 1164 \mathrm{~cm}^{-1}, 843 \mathrm{~cm}^{-1}$ can be clearly seen in Figure 1a-c. The typical PS absorption bands at $3047 \mathrm{~cm}^{-1}, 2929 \mathrm{~cm}^{-1}, 1440 \mathrm{~cm}^{-1}, 761 \mathrm{~cm}^{-1}, 697 \mathrm{~cm}^{-1}$ can be clearly seen in Figure 
$1 \mathrm{~b}-\mathrm{c}$. The band at $1042 \mathrm{~cm}^{-1}$ is related with $-\mathrm{SO}_{3} \mathrm{H}$ groups can be clearly seen in Figure 1b-c, but this peak intensity is weak due to hydrolysis of $-\mathrm{SO}_{3} \mathrm{H}$ groups. In addition, the characteristic peak of SPS/PANI and SPS/PANI/Ag is similar, but the peak intensity of SPS/PANI is greater than SPS/PANI/Ag. This phenomenon may be attributed to Ag nanoparticles making the peak intensity of SPS/PANI weaker. These results confirm the formation of pure PANI, SPS/PANI composites, and SPS/PANI/Ag composites.

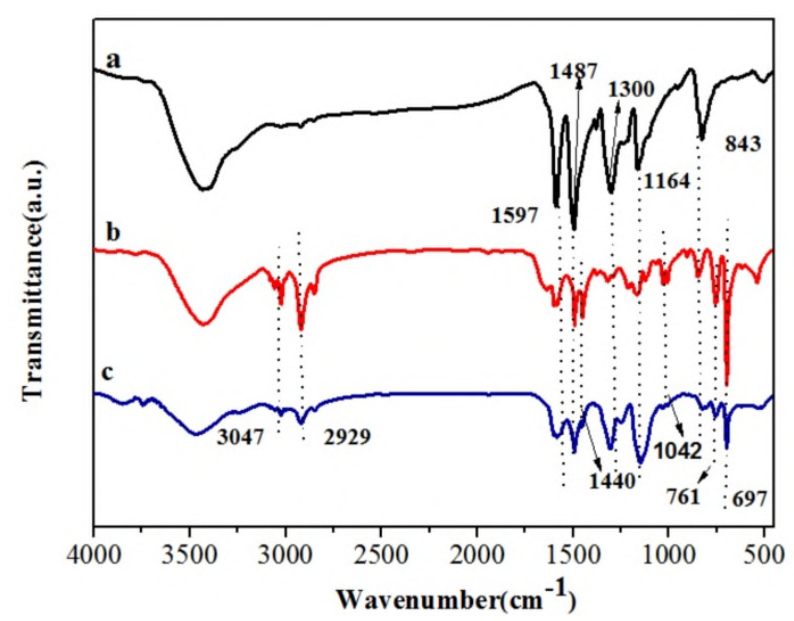

Figure 2. FTIR spectra of (a) pure PANI, (b)SPS/PANI composites, and (c) SPS/PANI/Ag composites

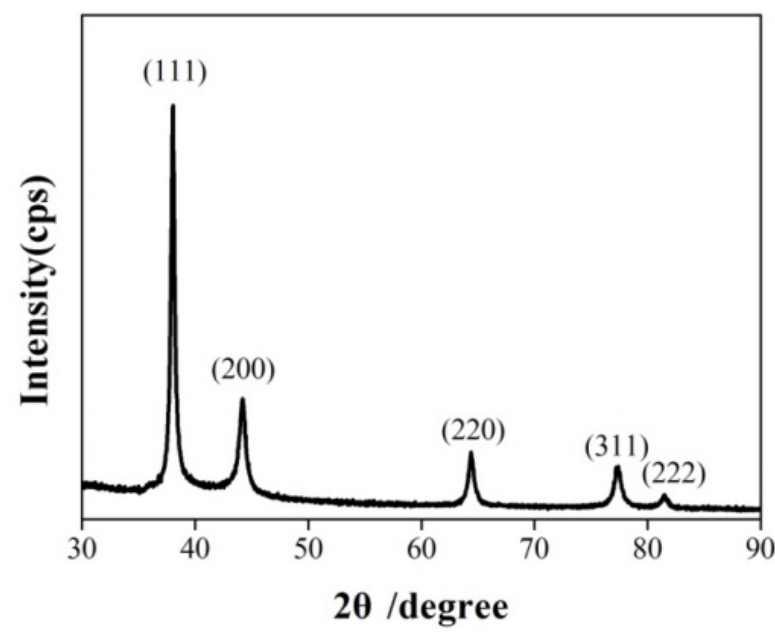

Figure 3. XRD patterns of SPS/PANI/Ag composites

The XRD patterns of SPS/PANI/Ag composites is shown in Figure 3. The XRD patterns of the SPS/PANI/Ag nanocomposites exhibits the sharp peaks at $2 \theta$ angles of $38.0^{\circ}, 44.1^{\circ}, 64.3^{\circ}, 77.2^{\circ}$, and $81.5^{\circ}$, which corresponds to (111), (200), (220), (311), and (222) crystal planes of Ag (JCPDS No.04-0783).(Liao et al., 2016) (Liao et al., 2017) (Liao et al., 2018 (Liao et al., 2017) This indicates that the Ag nanocrystallites have been obtained through the reduction of $\left[\mathrm{Ag}\left(\mathrm{NH}_{3}\right)_{2}\right]^{+}$ions with PVP.

The FESEM images and corresponding EDX spectra of pure PANI, SPS/PANI composites, and SPS/PANI/Ag composites have been shown in Figure 4. Figure 4a shows pure PANI particles are agglomerated. Figure 4b shows the SPS/PANI composites have many bulges on the surface of SPS microspheres. This indicates that PANI overlayer has formed on surface of SPS microspheres, but the PANI overlayer is not totally covered on the surface of SPS microspheres. It may be attributed to two possible reasons. First, the absence of strong electrostatic interaction between PANI and SPS. Second, PANI is a kind of rigid material, it is impossible to use PANI overlayer to cover completely SPS microspheres. Ag nanoparticles are found on the surfaces of the SPS/PANI composites with its size ranging from 50 to $70 \mathrm{~nm}$ (Figure S2c). Corresponding EDX spectra is shown in Figure 4d, Figure 4e, and Figure 4f. Note, Si element signals in high intensity observed in the all EDX spectra are originated silica wafer. As shown in Figure 4d, C and $\mathrm{N}$ element signals are observed in the EDX spectra of pure PANI. As shown in Figure 4e, C, O, S, and N element 
signals are observed in the EDX spectra of SPS/PANI composites. As shown in Figure 4f, C, O, S, N, and Ag element signals are observed in the EDX spectra of SPS/PANI/Ag composites. These evidences demonstrate these products have been successfully prepared.

(a)

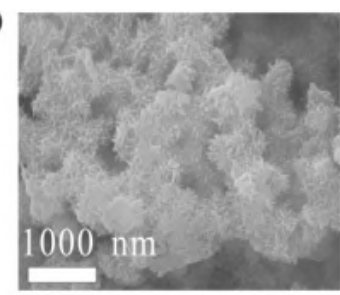

(d)

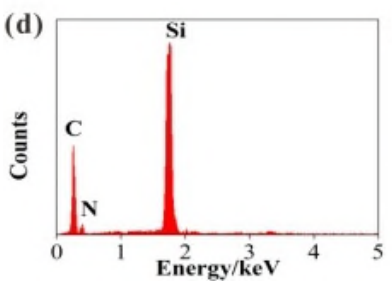

(b)

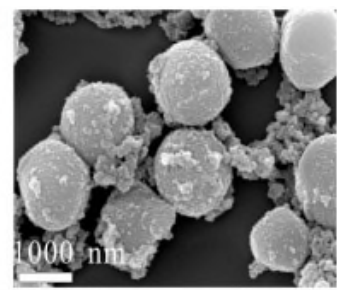

(e)

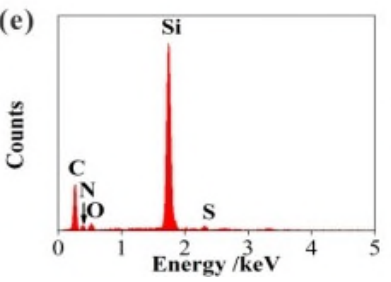

(c)
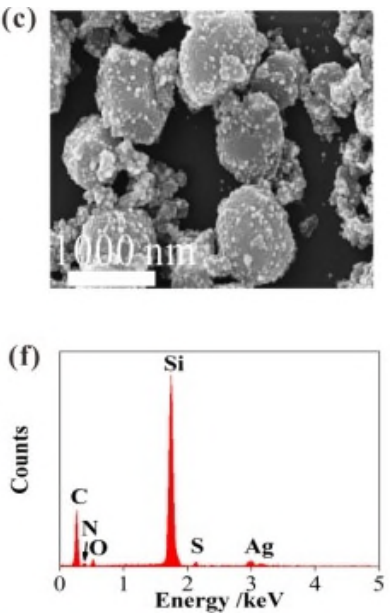

Figure 4. FESEM images and the corresponding EDX spectra of (a, d) pure PANI, (b, e) SPS/PANI composites, and (c, f) SPS/PANI/Ag composites

(a)

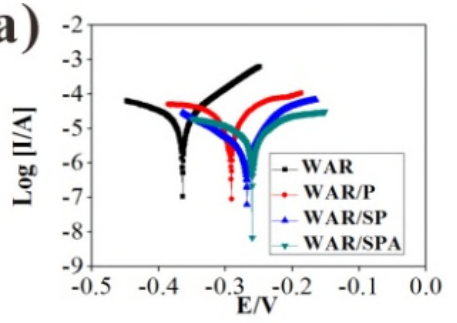

(c)

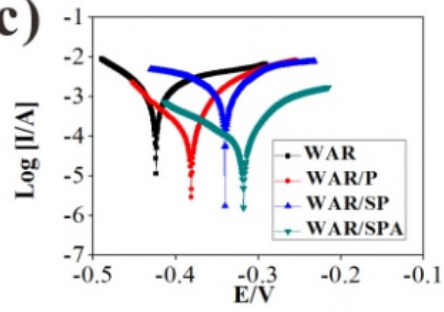

(b)

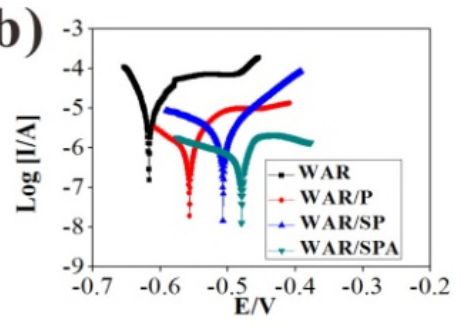

Figure 5. Tafel plots of WAR, WAR/P, WAR/SP, and WAR/SPA in $\mathrm{NaCl} 0.6 \mathrm{M}$ solutions (a), $\mathrm{NaOH} 1 \mathrm{M}$ solutions (b), and $\mathrm{HCl} 1 \mathrm{M}$ solutions (c), respectively

The Tafel plots analysis is used to evaluate the anticorrosive performance of WAR, WAR/P, WAR/SP and WAR/SPA. Figure 5 and Table 1 show that the corrosion potential of WAR/SPA is the highest, secondarily is WAR/SP, next is $\mathrm{WAR} / \mathrm{P}$, and the lowest is WAR in the following several corrosive environments. In other words, the anticorrosive properties of WAR/SPA is the best, secondarily is WAR/SP, next is WAR/P, and the worst is WAR in the following several corrosive environments. This result indicates that both WAR/SP and WAR/SPA exhibit improved enhanced anticorrosive properties. Moreover, WAR/SPA have better anticorrosive properties than WAR/SP. The enhancement is mainly attributed to the following two reasons. First, SPS microspheres are used as substrates can reduce aggregation of PANI particles.(Yang et al., 2005) Second, Ag nanoparticles have excellent environmental stability and anticorrosion property. (Liu et al., 2015) 
Table 1. Corrosion current ( $\mathrm{I}_{\text {corr }}$ ), corrosion potential ( $\mathrm{E}_{\text {corr }}$ ) of WAR, WAR/P, WAR/SP, and WAR/SPA in NaCl 3.5\% (w/w), $\mathrm{NaOH} 1 \mathrm{M}$, and $\mathrm{HCl} 1 \mathrm{M}$ solutions, respectively

\begin{tabular}{llll}
\hline Corrosive environment & Sample & $\mathrm{E}_{\text {corr }}(\mathrm{V})$ & $\mathrm{I}_{\text {corr }}(\mathrm{mA})$ \\
\hline \multirow{2}{*}{$\mathrm{NaCl} 0.6 \mathrm{M}$} & WAR & -0.363 & $6.607 \times 10^{-6}$ \\
& WAR/P & -0.291 & $3.467 \times 10^{-6}$ \\
& WAR/SP & -0.268 & $0.125 \times 10^{-6}$ \\
& WAR/SPA & -0.259 & $2.259 \times 10^{-7}$ \\
& & & \\
$\mathrm{NaOH} 1 \mathrm{M}$ & WAR & -0.616 & $2.291 \times 10^{-6}$ \\
& WAR/P & -0.556 & $1.819 \times 10^{-6}$ \\
& WAR/SP & -0.507 & $1.380 \times 10^{-6}$ \\
& WAR/SPA & -0.479 & $1.023 \times 10^{-6}$ \\
$\mathrm{HCl} \mathrm{1M}$ & & & $1.175 \times 10^{-3}$ \\
& WAR & -0.423 & $2.571 \times 10^{-4}$ \\
& WAR/P & -0.381 & $1.622 \times 10^{-4}$ \\
& WAR/SP & -0.339 & $1.355 \times 10^{-4}$ \\
\hline
\end{tabular}

\section{Conclusion}

In summary, we present a green approach to prepare SPS/PANI/Ag composites with enhanced anticorrosive properties through using SPS microspheres as substrates and utilizing PVP as reducing agent and stabilizing agent. FTIR, FESEM, and EDX results have confirmed the formation of pure PANI, SPS/PANI composites, and SPS/PANI/Ag composites. XRD patterns indicate that the obtained Ag nanoparticles are crystalline. Anticorrosive studies show that both SPS/PANI and SPS/PANI/Ag composites have enhanced anticorrosive properties in comparison to pure PANI in various corrosive environments.

\section{Acknowledgements}

We would like to acknowledge the Ministry of Education Key Laboratory for the Green Preparation and Application of Functional Materials for providing necessary facilities.

\section{References}

Kim, S., M., Lee, J., In, I., \& Park, S. Y. (2014). Formulation of Silver Nanowire-Polyaniline Hybrid Transparent Electrodes by Using Catechol-enriched Polyaniline. Chem. Lett., 43, 1453-1455. https://doi.org/10.1246/cl.140527

Yang, C., Wei, H., Guan, L., Guo, J., Wang, Y., \& Yan, X. (2015). Polymer nanocomposites for energy storage, energy saving, and anticorrosion. J. Mater. Chem. A, 3, 14929-14941. https://doi.org/10.1039/C5TA02707A

Han, J., Wang, M., Hu, Y., Zhou, C., \& Guo, R. (2017). Conducting polymer-noble metal nanoparticle hybrids: Synthesis mechanism application. Prog. Polym. Sci., 70, 52-91.

https://doi.org/10.1016/j.progpolymsci.2017.04.002

Yuan, C., Xu, Y., Zhong, L., Zhang, L., Yang, C., \& Jiang, B. (2013). Heterogeneous silver-polyaniline nanocomposites with tunable morphology and controllable catalytic properties. Nanotechnology, 24, 185602-185611. https://doi.org/10.1088/0957-4484/24/18/185602

Yang, M., Cao, L., \& Tan, L. (2014). Synthesis of sea urchin-like polystyrene/polyaniline microspheres by seeded swelling polymerization and their catalytic application. Colloid. Surf. A, 441, 678-684. https://doi.org/10.1016/j.colsurfa.2013.10.034

Liu, Y., Feng, X., Shen, J., Zhu, J., \& Hou, W. (2008). Fabrication of a novel glucose biosensor based on a highly electroactive polystyrene/polyaniline/Au nanocomposite. J. Phys. Chem. B, 112, 9237-9242.

https://doi.org/10.1021/jp801938w

Dai, X., Zhang, X., Meng, Y., \& Shen, P. (2011) Preparation of hollow carbon spheres by carbonization of polystyrene/polyaniline core-shell polymer particles. New Carbon Mater., 26, 389-395.

https://doi.org/10.1016/S1872-5805(11)60089-9 
Zhao, Q., Liu, Y., \& Wang, C. (2005). Development and evaluation of electroless Ag-PTFE composite coatings with anti-microbial and anti-corrosion properties. Appl. Surf. Sci., 252, 1620-1627. https://doi.org/10.1016/j.apsusc.2005.02.098

Deng, Z., Zhu, H., Peng, B., Chen, H., Sun, Y., \& Gang, X. (2012). Synthesis of PS/Ag nanocomposite spheres with catalytic and antibacterial activities. ACS Appl. Mater. Inter., 4, 5625-5632. https://doi.org/10.1021/am3015313

Liao, G., Chen, J., Zeng, W., Yu, C., Yi, C., \& Xu, Z. (2016). Facile Preparation of Uniform Nanocomposite Spheres with Loading Silver Nanoparticles on Polystyrene-methyl Acrylic Acid Spheres for Catalytic Reduction of 4-Nitrophenol. J. Phys. Chem. C, 120, 25935-25944. https://doi.org/10.1021/acs.jpcc.6b09356

Liao, G., Zhao, W., Li, Q., Pang, Q., \& Xu, Z. (2017). Novel Poly(acrylic acid)-modified Tourmaline/Silver Composites for Adsorption Removal of $\mathrm{Cu}$ (II) ions and Catalytic Reduction of Methylene Blue in Water. Chem. Lett., 46, 1631-1634. https://doi.org/10.1246/cl.170785

Liao, G., Li, Q., Zhao, W., Pang, Q., Gao, H., \& Xu, Z. (2018). In-situ construction of novel silver nanoparticle decorated polymeric spheres as highly active and stable catalysts for reduction of methylene blue dye. Appl. Catal. A, 549, 102-111. https://doi.org/10.1016/j.apcata.2017.09.034

Liao, G., Gong, Y., Yi, C., \& Xu, Z. (2017). Soluble, Antibaterial, and Anticorrosion Studies of Sulfonated Polystyrene/Polyaniline/Silver Nanocomposites Prepared with the Sulfonated Polystyrene Template. Chin. J. Chem., 35, 1157-1164. https://doi.org/10.1002/cjoc.201600816

Yang, Y., Chu, Y., Yang, F., \& Zhang, Y. (2005). Uniform hollow conductive polymer microspheres synthesized with the sulfonated polystyrene template. Mater. Chem. Phys., 92, 164-171. https://doi.org/10.1016/j.matchemphys.2005.01.007

Liu, Y., Gao, H., Chen, S., \& Wang, D. (2015). Ag Nanoparticle-Loaded Hierarchical Superamphiphobic Surface on an Al Substrate with Enhanced Anticorrosion and Antibacterial Properties. J. Phys. Chem. C, 119, 25449-25456. https://doi.org/10.1021/acs.jpcc.5b08679

\section{Copyrights}

Copyright for this article is retained by the author(s), with first publication rights granted to the journal.

This is an open-access article distributed under the terms and conditions of the Creative Commons Attribution license (http://creativecommons.org/licenses/by/4.0/). 